hypoxic-ischemic encephalopathy showed that a decrease in head circumference ratios of $>3.1 \%$ between birth and 4 months of age was highly predictive of the development of microcephaly before 18 months. Head circumference ratios were actual head circumference/mean head circumference $\times 100 \%$. They were correlated with severity of neonatal HIE and outcome at 18 months. (Cordes I et al. Early prediction of the development of microcephaly after hypoxic-ischemic encephalopathy in the full-term newborn. Pediatrics May 1994;93:703-707). (Reprints: Dr Alan Hill, Division of Neurology, British Columbia's Children's Hospital, 4480 Oak St, Vancouver, BC, Canada V6H 3V4).

COMMENT. A decreased rate of head growth in the first 4 months after acute, intrapartum HIE correlates with the later development of microcephaly and neurological sequelae in the full-term neonate as well as very low birth weight infants.

\title{
VASCULAR MALFORMATIONS
}

\section{TREATMENT OF CVA AND VEIN OF GALEN ECTASIA}

Optimal methods of evaluation and treatment of newborns with cerebral arteriovenous malformation associated with ectasia of the vein of Galen are outlined along with a case report of an inoperable malformation from the Dept of Pediatrics, Malarsjukhuset, Eskilstuna, and Dept of Neuroradiology, Karolinska sjukhuset, Stockholm, Sweden, and Centre Hospitalier Universitaire de Bicetre, France. The infant developed a general seizure at $10 \mathrm{~min}$ of age. She had a loud bruit over the skull and neck and congestive heart failure. Neurosonography showed a mass in the midline of the brain. CT confirmed a $\mathrm{A}-\mathrm{V}$ malformation and ectasia of the vein of Galen, complicated by in utero encephalomalacia and more recent ischemic injury. Endovascular occlusive treatment was not appropriate and the child died at 15 days of age. Transarterial embolization of feeding arteries using bucrylate (isobutyl cyanoacrylate) is now considered the treatment of choice, in the absence of contraindications such as brain damage, prenatal cardiomegaly, or evidence of multi-organ failure. A free interval between birth and development of cardiac failure are factors of favorable prognostic value. (Swanstrom S et al. Conditions for treatment of cerebral arteriovenous malformation associated with ectasia of the vein of Galen in the newborn. Acta Pediatr March

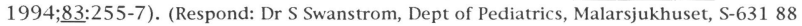
Eskilstuna, Sweden).

COMMENT. Rapid clinical deterioration due to cardiac failure is the common presenting feature of this syndrome. Transarterial endovascular occlusive treatment is available only in specialized centers. The rapid evaluation of patients suited for intervention is essential for successful outcome. The authors caution against the use of contrast material for CT and advise against any form of angiography unless therapy is contemplated at the same time. 